\title{
Introducing Collapse
}

The fall, like the rise, of a civilization is a highly complex operation which can only be distorted and obscured by easy simplification.

Mortimer Wheeler ${ }^{1}$

\section{CLIMATE APOCALYPSE IN THE NEWS}

As I sat down to work this morning with Radio 4 on in the background, I was intrigued to hear the BBC's newsreader announcing that the riddle of the mysterious Classic Maya collapse had finally been solved. ${ }^{2}$ I waited with baited breath to hear what the latest explanation would be, thinking it must be a slow news day for ancient history to have made it into the news mix. A moderate drought, she explained, was enough to cause the collapse of Maya civilisation around 1,100 years ago, which, she added, led to the Maya cities and pyramids being swallowed up by the rainforest. The announcer confided that, although solving the Maya collapse had long been a problem, archaeologists generally now preferred drought as the cause.

The whole report probably lasted no more than two or three minutes, an impressively short time in which to explain the fate of a long-lived and complex civilisation that had existed for hundreds of years, several times longer than modern nations like the United States or Australia. It was a problem that, as she rightly pointed out, had puzzled archaeologists and the curious for years. But I wondered what exactly I and other listeners were supposed to understand by 'collapse' and by 'Maya civilisation' - dramatic images of lost and abandoned cities reclaimed by nature were evoked, but would we all 
be imagining the same thing? I was curious too about which archaeologists she was referring to, and who had decided that 'most' of them preferred this conclusion. I briefly wondered whether I would no longer be obliged to complete this book about collapse ...

So, I diligently looked up the original paper that the news report was based on, just published in the journal Science. ${ }^{3}$ The paper was somewhat less definitive than the news report, but its argument was still clear enough. I found that the authors, two oceanographers, had studied the existing palaeoclimatic data, drawn from physical samples taken from three locations in northern Yucatan, Mexico. Like other researchers before them, they suggested that chemical analysis of cores taken from lake bottoms and from stalactites ('speleothems' - stalactites and stalagmites or cave calcites) indicated periods of reduced rainfall in Late Classic Maya times (the eighth and ninth centuries AD). This, they said, would have reduced the carrying capacity of the land, the amount of food that it could produce, which would in turn have caused the population to fall catastrophically, triggering 'significant societal disruptions'.

Rather than a new solution, this sounded like a well-known story of collapse due to some kind of environmental change with which human society could not cope, the main difference being that the authors were claiming that a more moderate reduction in rainfall could be blamed, rather than the massive droughts suggested by others. If a modest reduction in rainfall could have this effect, it suggested that the ecology and hydrology of the Yucatan Peninsula, the home of (some of) the Maya people, were particularly sensitive to change; a plausible hypothesis. But, given the long history of research on the problem of the Classic Maya collapse, and the number of publications, scholarly and popular, as well as television documentaries and even films on the subject, was that it? Rainfall slightly reduced, Maya collapsed and disappeared?

I was still left wondering what the authors really thought the Maya collapse was, and if this moderate reduction in rainfall could be enough to explain it. The news story had suggested a point of collapse around 1,100 years ago, $c$. AD goo, and the disappearance of the Maya, whereas the authors of the paper actually noted, quite rightly, that 'the disintegration of the Classic Maya Civilization was a complex process' taking two centuries. But their account still seemed very much to imply some kind of terrible event that would have involved a lot of death and unpleasantness. Did they imagine that many Maya 
simply died at once, that it was ultimately a kind of Malthusian population collapse? And what were these 'societal disruptions'? Their statement that the collapse 'involved a catastrophic depopulation of the region' seemed clearly enough to indicate that it was an ecological collapse they were thinking of, of the kind biologists might identify in any species or ecosystem.

I was left with an image of an empty landscape, and a population wiped out by a terrible natural disaster, yet it is difficult to square this with the idea of a complex two-century process of change, which the authors had introduced. Two centuries is a long time, time enough for significant changes in ways of life and attitudes, in political geography, and in material culture to occur. Admittedly, it can be hard to conceptualise past periods of time; as George Orwell said 'when you look backward things that happened years apart are telescoped together'. ${ }^{4}$ The stories implied some kind of 'back to square one' blow, from which the Maya, the few who survived, would have to start again amongst the ruins of their former glory. In this account, a fairly typical story of apocalyptic collapse involving a terrible disaster and death with a handful of survivors eking out a living in a post-apocalyptic age, the ancient Maya were helpless victims of circumstance.

The Maya are not the only ones to receive this treatment, although they are a perennial favourite - enigmatic, exotic, mysterious. In 2012, for example, The Times of India proclaimed that 'Climate killed Harappan civilization', a story also based on a research paper published in the Proceedings of the National Academy of Sciences of the USA (PNAS).5 The paper argues that a reduction in monsoon rainfall affected the complex river flows of the Indus basin, with rivers getting smaller, becoming seasonal, or even drying up completely. The agricultural basis of the Harappan urban sites was undermined. Yet there was no sudden ending, no killing stroke executed by the climate; the authors state soberly that: 'since approximately 3,900 y ago, the total settled area and settlement sizes declined, many sites were abandoned, and a significant shift in site numbers and density towards the east is recorded'.

Another similar story, entitled 'Climate change: The great civilization destroyer' appeared in the New Scientist in 2012, this time about the Mycenaean Greeks of the Late Bronze Age, $c .1200$ BC. ${ }^{6}$ This article, again based on a research paper, wanted to add the Mycenaean collapse to the list of peoples, societies, and civilisations supposedly brought to an end by climate change. ${ }^{7}$ 
These stories, and others like them, seem to represent the public image of collapse in the early twenty-first century and the cutting edge of archaeological and historical research. They tie in with our concerns over current climate change, and also with the vivid images we have of drought and famine. What these stories remind me of, and presumably others, are the graphic images of the victims of the tragic droughts and famines in Ethiopia in the 1980s. These came to international attention through the harrowing television reports shown around the world, which many in developed countries, seeing such things for the first time, found so shocking. Those images, and more recent ones that still appear regularly on television, seemed to show people stricken and emaciated, in abject poverty, with no food, water, or hope, people for whom circumstances were intolerable and for whom normal functioning society had ceased, people who would, without international aid, die where they sat, starving and thirsty. Would the Classic Maya, Harappan, and Mycenaean collapses have looked like this?

\section{STORIES AND COLLAPSE}

Probably not. The problem with collapse in the news and in many popular articles is that the stories they tell are grossly oversimplified, offering a caricature of history, a mythic version of historical change for our sound bite society; they are infotainment at its best. As we have seen already, one issue is the way that scientific research is transformed into news. In the first place, certain kinds of scientific research are more likely to get published in high-profile journals, and thus to catch the attention of news services. Journals such as Nature, Science and PNAS choose to publish novel and especially interdisciplinary research, research that has definitive results and conclusions - hard science style. Thus stories about new climate change linked to the fate of ancient societies are much more likely to reach a wide audience than a more circumspect paper in an archaeological journal.

Then the headline language used to describe collapse in popular sources (in the press as well as in documentary films) frequently serves to obscure the complex historical processes that were at work, turning them into cataclysmic events, and presents the peoples, states, or societies (and peoples) in question as static two-dimensional entities 
that could be wiped out in a blip. Too often, such reports, and the science papers on which they are based, fail to really consider what they are saying. What do we mean by collapse and what do we mean when we talk about the Classic Maya, the Harappans, or the Mycenaean Greeks, their cultures, their societies, and their civilisations? If we frame the questions simplistically, we are likely to get simplistic and unsatisfactory answers.

Despite their lack of substance, these stories have a great and understandable appeal, and it is worth thinking about this a little. What such stories really represent is a kind of quest romance, a kind of story as ancient and appealing as the oldest stories we know, which historian Ronald Hutton explains is 'one of the most popular and effective modes of expression for historical or archaeological research'. ${ }^{8}$ Researchers are heroes on a quest, who undergo a journey in which they apply their knowledge and skills, and eventually, and triumphantly, solve a seemingly insoluble historical conundrum.

Collapse stories appeal to our narrative desires in other ways too. They can be seen as both tragedy and parable. Tragedy originated as a specific kind of theatrical performance in ancient Greece, and tragic stories dealt with big and serious themes; plays were not simply 'art', but actively mirrored the politics and society of contemporary life and functioned 'as a powerful medium for the communication of ideas'. 9 They had a standardised plot in which the hero's journey is followed, his actions leading to a climax and then finally to a resolution, often the death of the hero. ${ }^{10}$ Read 'ancient civilisation' for 'hero' and we have a story of rise, zenith, and fall - stories of collapse which are blamed on human degradation of the environment seem to fit this pattern.

In tragedy, the hero usually makes a mistake, which leads to his fate; sometimes these errors are brought about by outside factors, such as divine intervention, but at other times there is some fatal character flaw. So in collapse we can see external factors blamed or errors made by the society that collapsed. Just as in tragedy, where the mechane allowed gods to enter the stage through the air, revealing the act of violence that resolved the play, collapse is often 'explained' by deus ex machina. ${ }^{11}$ Just as tragedy was a social art, witnessed and consumed by ancient audiences, our stories of collapse are spectacles, shared and consumed by modern audiences. 
Aristotle thought tragedy served an emotional or psychological purpose. He suggested that 'through pity and fear' there would be catharsis, an emotional purging in the audience. ${ }^{12}$ Nietzsche, thinking of tragedy, wrote of 'that lust which also involves the joy of destruction.' ${ }^{3}$ Others have suggested that tragedy provokes Schadenfreude, that in fact audiences enjoy the horrors of tragedy and the sufferings of its fictional hero, a kind of enjoyment which, however morally questionable it may be, seems real and commonplace. ${ }^{14}$ Does our witnessing of apocalyptic collapse, whether in print, on television, or on film, somehow fulfil us emotionally? Do we enjoy the spectacle and revel in stories of the destruction of others?

Perhaps. Nowadays this may be most evident in popular blockbuster films that project views of apocalyptic collapse with causes that reflect contemporary concerns. In recent decades, we have been treated to global disaster threatened by colliding comets in the 1998 film Armageddon, where disaster was narrowly averted through technology and guts, and also by the film Deep Impact where the ending was much more bleak, with millions perishing. In 2004 there was The Day After Tomorrow, a film which depicted a sudden climate change and the onset of a new ice age almost overnight. In 20o9, $20 I 2$ focussed on global disasters such as earthquakes and tsunamis, which killed millions, caused by the heating of the Earth's core by solar flares - a select few humans were able to save themselves in a number of 'arks', built in secret in China. The 2011 film Contagion, in more of a documentary style, explored the effects of a global pandemic, which caused the breakdown of social order; the film reflected real contemporary fears about possible pandemics such as SARS and $\mathrm{H}_{1} \mathrm{~N}_{1}$ flu.

Other myths of apocalyptic collapse too come to mind from our shared past culture. The flood myths shared by numerous cultures around the world are often taken to suggest that floods had a profound effect on people in the past, strong enough to warrant being passed down in stories, although floods, like other themes can have metaphorical rather than literal meanings. ${ }^{15}$ The flood myth recounted in the Mesopotamian Epic of Gilgamesh, and later the Christian Bible, have even inspired people to search for a real catastrophic geological event that may underlie the story - some suggest the flooding of the Black Sea. ${ }^{16}$ 
Also from the Bible we have the story of Sodom and Gomorrah, recounted in Deuteronomy 29:23. The cities were destroyed by God in his anger at the wickedness and vice of their inhabitants. But other kinds of destruction were also foretold. In Isaiah 17:1-2, a prophecy of the destruction of Damascus is given, in which it is predicted that the city will become a heap of ruins. The destruction of the mercantile city of Tyre by Nebuchadnezzar was also graphically prophesied in Ezekiel, which describes the utter destruction of one state by another. Destruction is a consequence of wrongdoing - a precursor to our modern environmental stories of collapse.

The Atlantis myth is a story of catastrophic and apocalyptic collapse par excellence. It has been a part of Western culture since Plato composed it in the early fourth century BC; we know it from his Critias and Timaeus. ${ }^{17}$ However, it is probably better known now than ever before; Alan Cameron notes it as the inspiration for over 20,00o books. ${ }^{18}$ A Platonic myth rather than a Greek myth, invented by a man devoted to exploring order, a crafter of ideal societies, and political utopias, the story relates how Atlantis, a fictional ideal state located on an island in the Atlantic, fell from grace as its once blessed and virtuous people grew corrupted and greedy over time, eventually trying to enlarge their empire and conquer the world. For this hubris Zeus wanted to punish them, and the ancient Athenians, who in contrast to the Atlanteans were still virtuous, defeated them in war, freeing all the conquered and enslaved peoples, and averting the threat from the invaders. Afterwards, 'there were earthquakes and floods of extraordinary violence, and in a single dreadful day and night all your fighting men were swallowed up by the Earth, and the island of Atlantis was similarly swallowed up by the sea and vanished'. ${ }^{19}$

Interpretations of the Atlantis myth abound as people make the story conform to their desires, but it seems clear enough that Plato, in the fourth century BC, was teaching his fellow Athenians (and others) to be mindful of their ambition and their priorities. ${ }^{20}$ They had been embroiled in the creation of an empire and had had a major conflict with Sparta, which led to defeat at the end of the fifth century BC. He perhaps wanted them to recall their ancestors in the earlier fifth century who had, somewhat against the odds, defeated the enormous might of the invading Persian king. Athens was the focus of the story; Atlantis represented an undesirable, avoidable fate. The 
story elaborates the age old aphorism that pride comes before a fall much like the story of Croesus and the Delphic oracle.

Alan Cameron notes that 'it is only in modern times that people have taken the Atlantis story seriously; no-one did so in antiquity'. ${ }^{21}$ Indeed, many have 'believed', including the British prime minister and Homeric scholar William Gladstone, and have tried to associate the Atlantis myth with 'real' history. ${ }^{22} \mathrm{~K}$. T. Frost in 1913 wrote that 'The search for Atlantis has given rise to so many conflicting views (most of them palpably absurd) that few scholars are prepared to take it seriously', before offering his own view, about which most modern scholars would express equal scepticism, that the story represented Minoan and Mycenaean history. ${ }^{23}$ Frost noted that while "it seems ... futile to seek for the geographical or geological site of a huge island now submerged. On the other hand a political and national disaster, a cataclysm in the usual instead of in the literal sense of the word, can destroy an ancient civilisation as completely as any flood'. ${ }^{24}$ But despite his comments others have continued to look, and to make associations with the archaeological, geological, and historical evidence of the Late Bronze Age Aegean, in particular the eruption of ancient Thera and its effects on Minoan Crete.

An interesting example of an apocalyptic story from the preHollywood blockbuster days that ticks the same boxes, and shows that our modern disaster discourse is no new thing, is the volcanic disaster narrative. ${ }^{25}$ This was a type of entertainment devised by pyrotechnical entrepreneurs, who produced 'volcano entertainments', spectacles with painted backdrops and sound effects, which became popular in the nineteenth century, but which originated in the eighteenth. They reflected increasing interest in geology and the natural processes of the Earth combined with excitement over the excavation of the buried city of Pompeii, which began in the 1740s.

In the 188 os, one such show, called The Last Days of Pompeii, was toured by the Pain family, who were fireworks manufacturers (Figure 1.1). It visited New York and London, among other places. In its first performance at Manhattan Beach, Coney Island, the show attracted more than a thousand spectators, with later shows attracting up to 10,000 . In June 1889, the Pains put on a modified version of the show, announced in the New York Times (9 June 1889): 


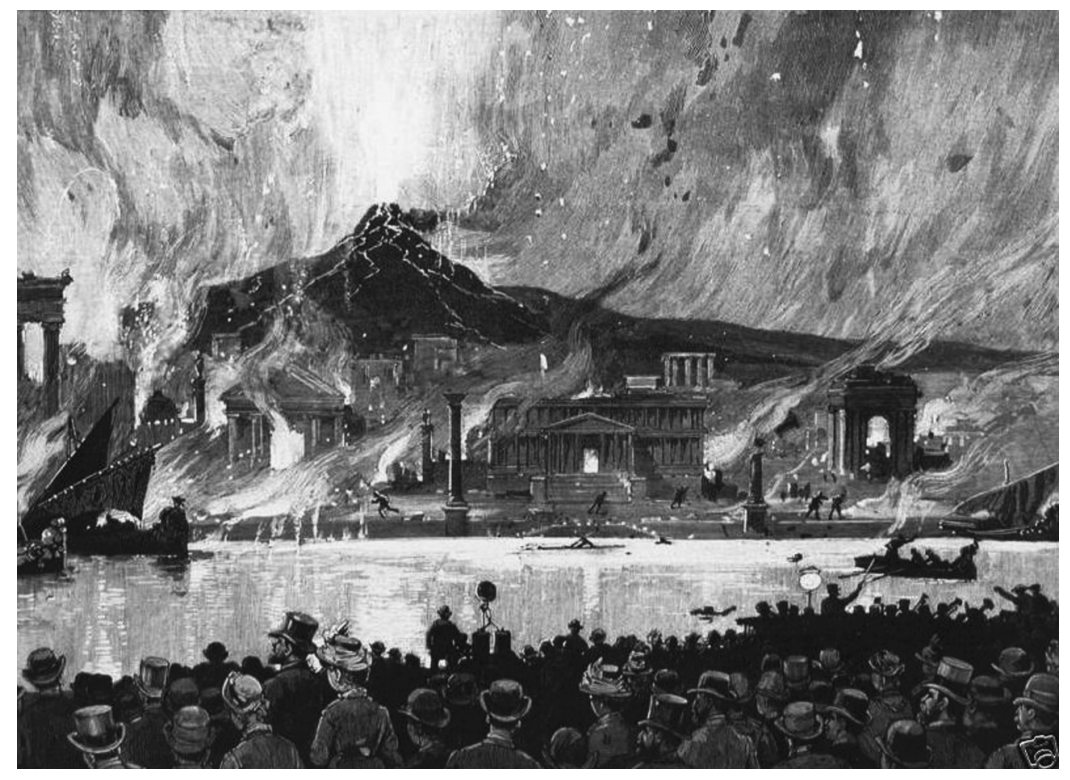

FIGURE 1.1. Graham Charles. Fireworks at Manhattan Beach - 'The Last days of Pompeii'.

Source: Harper's Weekly 25 July 1885, 476. General Research Division, The New York Public Library, Astor, Lenox and Tilden Foundations.

Beginning next Saturday night, 'The Last Days of Pompeii' will be presented nightly by Mr Pain at Manhattan Beach. It is not to be a revival of the show which he gave under the same name in $1^{8} 88_{5}$, but a much more elaborate and magnificent affair. There will be 4 oo people on the stage, a ballet of 36 dancers trained by Batiste Cherotte, master at the Metropolitan Opera House, a male chorus from the same place, soldiers, acrobats, jugglers, tumblers, wire-walkers, and others to assist in making the picture of a fete day. The display is to culminate in the destruction of the city by the fires of Vesuvius. ${ }^{26}$

In addition to their romantic and tragic appeal, stories of collapse are ideal fodder for the creation of modern parables for our time especially parables of human relationships with the natural environment. Examples of this are not hard to find, and they are frequently repeated in the literature, becoming factoids that purport to be straightforward historical facts. One noted environmental writer, Lester Brown, for example, in his book World on the Edge: How to Prevent Environmental and Economic Collapse, used as examples ancient Sumer and the Maya. The former collapsed because their successful 
irrigation systems eventually led to high salinity, resulting ultimately in food shortages and collapse. The latter chopped down too many trees, leading to soil erosion, and again, food shortages. Brown draws an explicit parallel between past and present: 'for us it is rising carbon dioxide concentrations in the atmosphere that are raising the global temperature, which could ultimately shrink grain harvests and bring down our global civilization'. ${ }^{27}$ The lessons we are to learn from the past are clear.

None of this is to say that there is only one 'correct' version of collapse that exists to the exclusion of all others, nor that the academic archaeological version (not that there is 'one' single version) is the best - in doing history there are many stories and perspectives that can be usefully brought into play. But it is important that we recognise the constructed nature of our ideas about collapse. I think Stephanie Moser puts it best:

The notion that researchers are solely responsible for creating meaning about the past is a false assumption that diverts our attention from the fact that representations have their own unique conventions and ways of communicating. Thus knowledge is not simply created by researchers and then diffused into popular culture (i.e. a one-way process); it is also created by many other kinds of discourse which in themselves shape the ideas of researchers. ${ }^{28}$

Our thinking on collapse, and the stories we tell of it, popular and academic, are reflections of our own times and concerns. As we read back through accounts of collapse from different times, we can see this influence clearly. ${ }^{29}$ But we must beware of over simplifying or skewing our accounts of past collapses just to turn them into lessons for modern society.

What I hope to have shown so far is that we often see collapse in very particular ways, which are structured by how we share knowledge - through stories or narratives. Collapse stories often bridge information and entertainment, fulfilling our needs on a variety of levels. Scientists are problem-solving heroes, societies are tragic characters, destined to fail, and collapse is a lesson to be learnt from. There is nothing inherently bad about this - it is human nature to make everything into a story. But if we really want to know about collapse, we have to begin by trying to see past the popular stories. A result of this, and one that many might find unsatisfying, is that we 
may end up without straight answers or simple plausible-sounding storylines; we might have to admit that sometimes (or a lot of the time) we do not know what happened or who or what was to blame for something that we think was going on.

\section{WHAT IS COLLAPSE?}

Before we get too far along, we should think about what collapse actually is and what kind of things can collapse. Assumptions about and lack of definitions of collapse are two of the problems in how it is represented. Very often, the implication is that collapse is some kind of apocalyptic event - everyone starves and the monuments of a civilisation decay and are lost only to be rediscovered much later on, posing a riddle to explorers and archaeologists. As Joseph Tainter suggests, many 'authors assume that we know what it means, without individual, cultural, or temporal variation'.$^{\circ}$ However, there is no guarantee that we are in fact all sharing the same idea of what collapse is.

Describing the Maya collapse, archaeologist Arthur Demarest takes the problem a step further, blaming controversies over interpretation not only on assumptions about what collapse is, but also on confusion over what is collapsing:

Recent discussions of the collapse of civilizations have demonstrated that terminological ambiguity creates much of the controversy regarding comparative issues, including differences in the interpretation of specific cultural historical episodes. The meanings of terms such as 'collapse' and 'decline' are far from obvious. Furthermore, ambiguity about what precisely is 'collapsing' (e.g. 'civilization,' 'state,' 'kingdoms,' 'tradition,' 'society') generates more disagreement than do problems of historical or archaeological interpretation..$^{1}$

But there are definitions of collapse, and of what it might apply to, and I shall introduce and discuss some of those next.

Joseph Tainter's 1988 book The Collapse of Complex Societies is still probably the most referenced book on collapse; the author has written much about collapse, complexity, and sustainability. His definition of collapse goes like this:

Collapse ... is a political process. It may, and often does have consequences in such areas as economics, art, and literature, but it is fundamentally a matter 
of the socio-political sphere. A society has collapsed when it displays a rapid, significant loss of an established level of sociopolitical complexity. The term 'established level' is important. To qualify as an instance of collapse a society must have been at, or developing toward, a level of complexity for more than one or two generations. The demise of the Carolingian Empire, thus, is not a case of collapse - merely an unsuccessful attempt at empire building. The collapse ... must be rapid - taking no more than a few decades - and must entail a substantial loss of sociopolitical structure. Losses that are less severe, or take longer to occur, are to be considered cases of weakness and decline..$^{2}$

Tainter sees collapse very specifically as a political process connected to the degree of complexity of a society. Human societies become more complex as a response to the problems and opportunities that they face, and through collapse they become less complex. ${ }^{33}$ Collapse then is a rapid process of simplification - where rapid means not instantaneous, but perhaps a few decades. Importantly, in Tainter's way of thinking, collapse itself is an adaptation not simply a failure.

What does this definition apply to? In his main examples, Tainter writes about the Western Roman Empire, the Classic Maya, and the Ancestral Puebloans of southwestern North America. These are three quite different entities, operating at different scales. The first was a large empire; the second a group of independent but competitive states of varying size making up what we could call a 'culture zone'; the third is a smaller single culture. So in Tainter's view, political collapse can happen to a range of 'things'. We might wonder, however, whether all of these are really comparable.

George Cowgill and Norman Yoffee discussed what collapse applies to in another key publication from 1988, The Collapse of Ancient States and Civilizations. They suggest that we should 'clearly differentiate between state, society and civilization, and use the last term in a specifically cultural sense'. ${ }^{44}$ Collapse occurs within civilisations, which are the 'cultural tradition[s] in which the state is embedded,' consisting of 'literature, customs, languages'.35 To some, this may seem like academic semantics, but it is important. Often we read or hear about the collapse of civilisations, but Roman, Maya, and Ancient Puebloan civilisations did not collapse at all - all three survive, transformed, to this day. It is specific political regimes that collapsed, social systems that changed, and religious and ideological systems that were transformed and/or rejected. 
Take another example - Mesopotamian civilisation. Jane Rempel and Norman Yoffee asked the question, 'did Mesopotamian civilisation end?' They emphasised that while politically Mesopotamia contained many different states and empires over the years, which rose and fell, and eventually the whole region fell prey to even bigger empires passing through Persian and then Macedonian and Greek hands, 'Mesopotamian civilization did not undergo a similar collapse. ${ }^{36}$ That is not to say it did not change, it certainly did - it transformed over long years, but it did not collapse in the blink of an eye. The cuneiform writing tradition could be taken as an index of the presence of Mesopotamian civilisation and its disappearance as late as the third century AD could be said to mark the end of Mesopotamian civilisation. ${ }^{37}$ But this single indicator is an arbitrary one - a civilisation is a set of features that transform at different rates (and with different implications for the people and societies in question).

There is no need to see such transformations as decline - the value of cultural items and practices such as writing changes, as do the ways people seek to construct their personal and cultural identities. Likewise with the end of the Western Roman Empire. Its political system collapsed in the fifth century AD, its territory fragmenting into multiple independent states, but Roman civilisation did not collapse. It had always been changing, and this did not end abruptly with the death of the last Western emperor; the Roman heritage remained alive, being reused, reinterpreted, and transformed by the people who inherited it - in the twenty-first century the Americans still place importance on the concept of liberty, and retain senators and a senate.

What about famous examples of collapse such as the Greenland Viking communities, or the lost city of Roanoake, or Rapa Nui? In the former case, we have two communities that were eventually abandoned - but these did not collapse in Tainter's sense, and the latest research suggests they were abandoned by their inhabitants in good order rather than that they fell into chaos and calamity with everyone starving to death or killing each other. $3^{8}$ With Roanoake (the City of Raleigh, on Roanoke Island, Virgina), the English settlement founded in North America in 1587 , we have an example of a mystery - another settlement abandoned - but again not a collapse 
in the view of many. ${ }^{39}$ And what about Easter Island? Whether there was a collapse - a simplification of Rapa Nui society - at some point before Europeans arrived is controversial, as we shall see later on. In all these examples of supposed collapse, what probably happened is far less dramatic than the apocalyptic stories we are often presented with.

Many authors who write about collapse cite Tainter in their own lists of references, but not everyone strictly follows his definition of collapse. Jared Diamond, one of the most well-known popular writers on collapse, gave a definition in his 2005 book Collapse that is clearly drawn in part from his reading of Tainter and other thinkers on collapse, but it differs in key respects:

By collapse, I mean a drastic decrease in human population size and/or political/economic/social complexity, over a considerable area, for an extended time. The phenomenon of collapse is thus an extreme form of several milder types of decline, and it becomes arbitrary to decide how drastic the decline of a society must be before it qualifies to be labelled as a collapse. $4^{\circ}$

The first thing we should note is that, unlike Tainter, Diamond emphasises 'drastic' decreases in population over a wide area and long period of time. This reflects not only the common view of apocalyptic collapse, but also Diamond's background in ecology and biology, where collapse is something that happens to populations in ecosystems (think of the mysterious 'colony collapse disorder' that has affected bee populations in recent years). This focus on population and disaster also follows from Thomas Malthus' influential An Essay on the Principle of Population, published in 1798, in which populations grow until they are checked by some kind of catastrophe. The focus on population in Diamond's definition is almost the opposite of Tainter's view that collapse is primarily a political process.

It is easy to imagine that a demographic collapse would be a terrible thing - something that would by its very nature have to be brought on by plague epidemics or famines caused by extreme droughts or climate change or damage to a society's supporting environment, which reduced its carrying capacity. Such a disaster would surely have serious repercussions for any society - even possibly bringing about its demise (though clearly the medieval European states survived the 
massive disruption and population loss caused by the Black Death). Thus, Diamond envisions the Greenland Viking's collapse as:

sudden rather than gentle, like the sudden collapse of the Soviet Union [the Eastern settlement was] like an overcrowded lifeboat ... famine and disease would have caused a breakdown of respect for authority ... starving people would have poured into Gardar, and the outnumbered chiefs and church officials could no longer prevent them from slaughtering the last cattle and sheep ... I picture the scene as ... like that in my home city of Los Angeles in 1992, at the time of the so-called Rodney King riots ... thousands of outraged people from poor neighbourhoods ... spread out to loot businesses and rich neighbourhoods. $4^{1}$

A focus on demographics conjures up a stereotypical descent into a dark age largely devoid of people and of the kinds of activity that comprise civilised life. Whereas for Tainter a political collapse could have repercussions in other areas of life and society, including being a cause of depopulation, for Diamond it is primarily depopulation that is collapse.

We have looked at two quite different visions of collapse, both drawn from works attempting to give general explanations of why collapse happens - one taking an economic perspective, the other an environmental one. But what about archaeologists themselves, how do they see collapse? In an important book about collapse and regeneration, from 2006, entitled After Collapse: The Regeneration of Complex Societies, Glenn Schwartz explains:

In the archaeological literature, collapse usually entails some or all of the following: the fragmentation of states into smaller political entities; the partial abandonment or complete desertion of urban centers, along with the loss or depletion of their centralizing functions; the breakdown of regional economic systems; and the failure of civilizational ideologies..$^{2}$

This broad description is different again. It does not necessarily describe the simplification of a given society, unless we see the fragmentation of empires or states as simplification, nor does it necessarily involve demographic collapse, although this can be indicated by the abandonment of sites (but this can also indicate the nucleation of population at a few sites or a shift in subsistence strategies). But rather than insisting on a single meaning, it gives us a number of descriptive features of collapse that we can tie to specific examples, 
and these reflect well how archaeologists apply the term 'collapse' in practice.

A more recent definition from their 2012 paper is given by archaeologist Karl Butzer and environmental historian Georgina Endfield, who suggest that:

Societal collapse represents transformation at a large social or spatial scale, with long-term impact on combinations of interdependent variables: (i) environmental change and resilience; (ii) demography or settlement; (iii) socioeconomic patterns; (iv) political or societal structures; and (v) ideology or cultural memory. 43

Although there is some overlap with the previous definitions, this one is different again, since it defines collapse as large-scale transformation with a number of possible impacts on five interlinked areas. One problem with this definition is that there is no idea of the timescale of such transformation - are such transformations rapid? Does collapse as transformation have to be measured in a few years, in decades, or can it take place over centuries, in which case how does it differ from plain 'change'? Also, can we equate 'demography' with 'settlement' that is, equate population with how populations are spread through the landscape?

Another problem (depending on your point of view) is that state formation or ideological changes, such as new systems or ideologies of power, may count, in this definition, as episodes of collapse. Was the pyramid age of Egypt an era of collapse because of its new centralisation and a new system of ruler-focused monumental propaganda? Can either the founding of the Roman Empire (from an oligarchical republican system), the Christianisation of Rome (or indeed Europe), or the extension of the franchise to women in the UK, as profound real and ideological changes, count as collapses?

Finally, let us include a definition from the sustainability literature, as given by Marianne Young and Rik Leemans:

Let us define collapse as any situation where the rate of change to a system:

- has negative effects on human welfare, which, in the short term, are socially intolerable;

- will result in a fundamental downsizing, a loss of coherence, and/or significant restructuring of the constellation of arrangements that characterise the system; and 
- cannot be stopped or controlled via an incremental change in behavior, resource allocation, or institutional values. 44

This definition is drawn from the results of a Dahlem workshop, published in 2007 as Sustainability or Collapse? An Integrated History and Future of People on Earth. 45 These authors, as with some of the others, do refer to timescales - since change is normal, collapse represents a change in its rate where certain effects are present, including simplification and 'socially intolerable' effects on human welfare. It is also seen as an unstoppable process - one that cascades from changed situation to changed situation, taking the unit considered further away from a particular first set of circumstances.

The definition is reminiscent of the idea of failed or failing states, an equally inexact concept popular since the 1990s, which is of clear concern to policy makers seeking to ensure that states become or remain sustainable and do not collapse. Of these, Cojanu and Popescu explain:

There is a growing recognition of the threat to international security posed by failed and fragile states, often marred by serious internal conflict that also has the potential of destabilizing neighbouring states and providing ungoverned territory that can provide safe haven for terrorists.

The inability of their governments to provide basic services is considered a significant contributory factor. Poorly performing developing countries are linked to humanitarian catastrophes; mass migration; environmental degradation; regional instability; energy insecurity; global pandemics; international crime; the proliferation of weapons of mass destruction, and, of course, transnational terrorism..$^{6}$

Socially intolerable conditions can be quite a tricky concept to define. It may simply mean that living conditions become much worse intolerably so, for a given period of time. They may, however, become tolerable as people's expectations and values change. For whom (and for how many) do conditions have to be intolerable? The slave miners in the Roman world, the child miners of nineteenth-century Britain, or other exploited or socially excluded groups surely lived in conditions that others might find intolerable ... But these were normal features of 'successful' societies that were not collapsing. We might also, when we take society to refer to an identifiable social unit like an empire or state, think of circumstances that the system itself, rather than its people, is unable to bear. 
Most reasonable people would expect there to be some leeway in language usage; after all, we usually adopt or create terminology to help us think about the thing we are trying to describe, and not as an end in itself, as Patrick L. Gardiner reminds us:

Generalizations about revolutions, class-struggles, civilizations, must inevitably be vague, open to a multitude of exceptions and saving clauses, because of the looseness of the terms they employ ... But this is not to criticize such generalizations provided that they are not expected to do more work than they are fitted for. The scientific model of precise correlation is misleading in any attempt to comprehend the role of these generalizations in history, where they function frequently as guides to understanding. 47

Each definition of collapse brings with it different observations, ramifications, and repercussions. There is little of the apocalyptic to be seen, except perhaps in Diamond's and Young and Leemans' ideas, and the demographic definition is not one that archaeologists or historians usually use, except in specific cases such as collapse of native populations during instances of European colonialism. Much more frequently, collapse is used to mean the fairly rapid ending of states (including empires and much smaller entities), which itself can involve fragmentation into smaller units, simplification of political and social systems, change in urban settings, redistribution of population in the landscape, and changes in ideology made visible in architecture and the arts.

Many archaeologists agree that collapse often affected the elite members of societies most - or at least most visibly - and that those least affected (at least in some ways) would be the peasant farmers that made up the bulk of the population in pre-industrial societies. Thus collapse could be 'socially intolerable' to the elite but welcomed by 'middle classes' or others. But it is also true that collapse would have had effects that ran through a whole society to some extent. Fragmentation could bring instability and conflict, driving down agricultural production, trade, and exchange, all of which might affect the population levels, while the end of rulership, its specific ideology, and all that went with it would have had its own set of economic and social effects.

At any rate, whenever we think about collapse, it is a good idea to be critical - not for the sake of argument, but in order to grasp 
more fully what we (and others) actually mean and what we are really exploring.

\section{WHAT COLLAPSED?}

In Tainter's definition, collapse is something political that can happen to any established society - ones that are both more complex and less complex. But in practice, people apply collapse to many different kinds of 'units', and so I want to take a step back and consider the kind of units that collapse is said to happen to and to think about the implications of this. This is important because many authors take a comparative view of collapse, yet it is not always clear why some examples of collapse are thought to be comparable with others. To begin with, it may be helpful to consider the variety of entities that we encounter in the modern world, if only to remind us of some of the different categories involved.

Nowadays, we tend to think about the world as carved up into fixed territorial political units that we call countries, states, or nations, and which we often refer to generally as 'societies', owing to their nature as politically and socially defined in-groups in which people imagine a common identity. These may often be the biggest unit for which we have certain legally defined relationships and statuses, and a strong sense of identification. Some states, Switzerland, China, the United Kingdom, or Spain, for example, are multi-ethnic and multilingual, while in others, such as Korea or Japan, more stress has been placed, in recent times at least, on ethnic and cultural homogeneity.

Of course, there are also bigger entities like the European Union, in which many Europeans are voting citizens, but it is unclear whether this legal and political entity is also something with which many of its citizens strongly identify, in contrast with their other identities. There are other concepts that are made use of, such as 'westernness', 'Arabness', or 'Asianness', which are grounded in cultural or behavioural commonalities and sometimes in the idea of shared cultural heritages - sometimes equated with that loose idea of 'civilisations'. Much of Europe, and therefore the USA and other recent states, share an origin rooted partly in Roman and classical heritage. Some transnational identities and institutions are neither 'national' nor 'ethnic' and are based instead on religious or other affiliations - Catholicism 
is a prime example of an enduring non-ethnic group identity, Islam is another.

'Nation' can also refer to people who identify themselves as a unit, on the basis of some (possibly imagined) shared descent, ethnicity, or 'national' identity, for example. Nations may be non-sovereign groups, or groups with a degree of autonomy either within one or several sovereign states - the 30 million Kurds who live in Turkey, Iraq, Iran, and Syria, for example, or native American groups, are nations. Tribal or aboriginal groups elsewhere, within states, may also sometimes be considered as nations. In the past, as in the present, states and nations do not necessarily overlap territorially - empires and states may incorporate different peoples in different ways. In classical Greece, the helots of Sparta, Messenian Greek slaves owned by the state, were part of the state only to the extent that the state claimed ownership of them, keeping them subjugated for centuries. Despite this situation, a Messenian identity continued to exist and the Messenian state was reconstituted after the battle of Leuctra in 371 BC..$^{8}$

\section{WHAT ARE WE COMPARING IN PAST COLLAPSES?}

A brief glance at some of the examples rostered in comparative approaches to collapse shows that many different kinds of units are often considered together (Table 1.1). We can see empires, such as the Akkadian and Roman; cases that may be empires or states, such as Han China, Tiwanaku, and Wari; states like Uruk and Old Kingdom Egypt, and Axum. We can also see what may be best described as 'culture zones', including the Classic Maya, Crete and Late Bronze Age Greece, and Mesopotamia, which were made up of numerous independent states and other possibly non-state communities, which nevertheless shared a degree of cultural and sometimes linguistic similarity (probably the Harappan/Indus Valley societies fall into this category too).

Other units are included too - societies that might not be considered 'state level', such as the Ancestral Puebloans and Rapa Nui (Easter Island), and communities that were part of larger cultural groups such as the Greenland Norse. The very prehistoric 'Natufians' were not a people - the name refers to a more sedentary culture that appeared among hunter-gatherer communities in the Near East. ${ }^{49}$ 
TABLE 1.1. Objects of study in works on collapse

Tainter (1988)

Yoffee and Cowgill (1988)

Weiss and Bradley (2001)

Diamond (2005)

Schwartz and Nichols (2006)

Redman et al. (2007)

Costanza et al. (2007)

(In the same volume)

Butzer and Endfield (2012) (and others)
Ancestral Puebloan, Classic Maya, Roman Empire (plus many other shorter case studies)

Classic Maya, Han China, Mesopotamia, Mesoamerica, Roman Empire

Natufians; Uruk; Akkadian Empire, Old Kingdom Egypt, Harappa IIIB; EBA III Palestine, LBA Greece, Crete; Moche; Tiwanaku; Classic Maya; Ancestral Puebloan

Ancestral Puebloan, Greenland Norse, Easter Island, Classic Maya

Angkor, Classic Maya, LBA Greece, Old Kingdom Egypt, EBA Syria, Tiwanaku, Wari

Old Kingdom Egypt, China, Mesopotamia, Harappa, Bal He Kuk, Classic Maya, Hohokam

Classic Maya, Western Roman Empire, Northern Mesopotamia

Akkadian Empire, Axum, Cyprus, Greco-Roman Fayum, Iceland, Greenland Norse, Islamic Mesopotamia, Old/New Kingdom Egypt, Norse

Greenland,

Classic Maya,

Source: Tainter, J. A. (1988). The Collapse of Complex Societies. Cambridge: Cambridge University Press; Yoffee, N. and Cowgill, G. L. (eds.). (1988). The Collapse of Ancient States and Civilizations. Tucson: Arizona University Press; Weiss, H. and Bradley, R. S. (2001). 'What drives societal collapse?' Science 291: 6o9-610; Diamond, J. (2005). Collapse: How Societies Choose to Fail or Succeed. London: Penguin; Redman, C. L. et al. (2007). 'Group report: Millenial perspectives on the dynamic interaction of climate, people, and resources.' In Costanza, R., Graumlich, L. J., and Steffen, W. (eds.). Sustainability or Collapse? An Integrated History and Future of People on Earth. Cambridge: Dahlem University Press and Massachusetts Institute of Technology, pp. 115-148; Costanza, R., Graumlich, L. J., and Steffen, W. (eds.). (2007). Sustainability or Collapse? An Integrated History and Future of People on Earth. Cambridge: Dahlem University Press and Massachusetts Institute of Technology; Schwartz, G. M. and Nichols, J. J. (eds.). (2006). After Collapse: The Regeneration of Complex Societies. Tucson: University of Arizona Press; Butzer, K. W. and Endfield, G. H. (2012). 'Critical perspectives on historical collapse.' Proceedings of the National Academy of Science 109(10): 3628-3631 - see also other articles in PNAS 109(10)). 
It seems clear from the list that these are not all identical types of unit, but they are each supposed to have experienced some kind of collapse - the Western Roman and Akkadian Empires ended; the Easter Islanders descended into famine, violence, and chaos, losing their high culture; the Maya abandoned their pyramids and cities; and the palaces of Late Bronze Age Greece and Crete were burned and deserted. But are they really comparable, as some claim? To me they often seem to be very different, and so grouping them together, and even assigning the same causes to their collapses, as some wish to do, seems problematic. Imperial collapse - the fragmentation of a single unit into multiple units, seems different from a sudden depopulation, or to collapses that are said to happen across entire culture zones, which involve widespread desertion. An empire is a clear political unit, but a culture zone is not, even if states or units with a culture zone sometimes build bigger states (or empires) within it, as happened among the Classic Maya, Mesopotamians, and perhaps others.

Taking a cue from Arthur Demarest, I think we can divide up the units into five kinds, in a fairly arbitrary and approximate scheme, which may nevertheless help us to see things in a clearer light, and perhaps to understand problems in previous approaches to collapse where many examples are seen as straightforwardly comparable - an approach which helps generate definitions of collapse that are then necessarily very broad, and not necessarily very satisfying (Table 1.2). Any comparative account should surely pay attention to the nature and comparability of the units under investigation.

\section{Individual Communities}

Individual communities might include examples such as medieval British villages, or the two small medieval Norse communities in Greenland, as well as 'mysterious' disappearing colonies like the English settlement of Roanoke in North Carolina..$^{\circ}$ The latter two were not really self-sufficient or sustainable 'societies' in themselves, rather they were precarious and vulnerable outposts of established societies, which shared in an on-going parent culture. It can be noted that the constant and normal ebb and flow of British villages did not bring about, and does not represent, any widespread 'British' collapse. 
TABLE 1.2 Five units implicated in collapse

1. Individual communities

2. Political units - empires, states, dynasties, chiefdoms, etc.

3. Cultural units, civilisations, ideologies, lifestyles ('archaeological cultures'? - Natufian types?)

4. Systems, including 'world-systems'

5. Populations, peoples

\section{Political Units}

By political units, I generally mean the kind of units that Tainter calls societies. Collapse is frequently associated with empires in which a particular state or group come to dominate other people and groups over a wider area. Empires are not simply nations but are processes that stitched together peoples and places often by force, setting in train numerous changes at home and in their provinces - recall the Roman poet Horace's famous claim that 'captive Greece took her savage victor captive, and brought the arts to rustic Latium' (Epistles 2.1.156).

Non-imperial (or not clearly imperial) states or 'kingdoms' also collapse (although a state can be considered as made up from smaller units, and is thus 'imperial' in a sense). Teotihuacan would be an example of this, but so would the Late Bronze Age Greek states such as the Pylos polity. Greek palace states seem to have been built up from smaller units, pieced together presumably through diplomacy and violence - in which we might always find those people and groups resistant to state building groups. Some Classic Maya rulers too welded together bigger units from smaller independent ones, gaining influence over other centres and over wider areas. Even Egypt, often seen as a unified upper and lower state (pharaohs wore the double crown representing unity), could decompose into smaller constituent parts.

Another area that can cause confusion is the notion of dynasties. In the history of some areas, such as China, Egypt, and Mesopotamia, it is customary to speak of dynasties. A dynasty is commonly thought of as a ruling family, or house, but the term 'dynast' really just means a powerful person (think of 'dynamo'). Historically speaking, dynasty is also a term used where we should really think of distinct political 
entities that were independent, rivalrous, and that effectively created new states or empires in competition with others. China from the Bronze Age Shang to the early modern Qing was really many different entities in the same way that the Ur III dynasty of Mesopotamia was different from the Akkadian Empire. Progressivists might think of the later states as 'evolved' from, or more developed versions of, the former, and of course there are connections, often deliberately made, between the later and earlier states. Nevertheless, it may be more helpful to remember that they were in some senses different entities and not simply earlier and later iterations of the same thing.

The Shang, for example, were only one 'dynasty' of ancient China, and the term Shang also refers to bits of material culture (bronzes in particular), a cultural complex, and even a people, their phase usually divided into three and based at perhaps successive sites including Erlitou, Erligang, and with the better known Late Shang at Anyang. ${ }^{51}$ They were not alone in the area we know now as China - there were other polities with their own dynasties. Much later, the Qing dynasty in China, who originated among the northern Jurchen people, took around a century to incorporate its eventual territory into a single state..$^{2}$ Between Shang and Qing, during the Qin dynasty/state (221$210 \mathrm{BC}$ ), there developed concepts of unity in China, including the idea of Zhongguo, the 'Central Kingdom', of tianming, 'mandate of heaven', and tianxia, 'all under heaven', which could be adopted as principles of interaction, as ideologies, by subsequent diverse actors and ethnic groups, and the idea of a common cultural core was codified, preserved, and studied in literature.53 Such notions of unity developed in Egypt and Mesopotamia too, to varying degrees though it was stronger in Egypt.

\section{Cultural Units and Lifestyles}

Here we have to be careful as we enter the realm of type three, for type three units are not really solid political structures at all, rather they constitute nebulous categories that employ materials or other cultural features as the parameters of a definable unit. So although people have talked (and some still do) about Maya or Mycenaean Empires, neither the Maya nor LBA Greeks formed a single political society; they were connected, yes, and shared elements of material 
culture that allow us to consider them, in archaeological terms, as 'a culture' (which in archaeology never necessarily indicates 'a people'). But their inhabitants may never have shared a common ethnic identity, even if they spoke the same language, and likely they considered their identity in more local terms (as did the citizens of classical Greek city-states - and those Greeks did also eventually share a notion of common ethnic identity). Like Mesopotamia or ancient China, independent cities grew up together, converging to some extent through a process of mutual development and contact known to archaeologists as 'peer polity interaction'.54 Colin Renfrew explains that this:

... designates the full range of interchanges taking place (including imitation and emulation, competition, warfare, and the exchange of material goods and of information) between autonomous (i.e., self-governing and in that sense politically independent) socio-political units which are situated beside or close to each other within a single geographical region, or in some cases more widely. .55

What about civilisations? It is also common enough to find references to Maya, Mycenaean, or Roman civilisations, and, like culture (or the culture of a particular people), for which it is sometimes a synonym, it can tend to imply a unity that, while real enough in some ways, can also distort our view of complex and diverse cultures. Although there may sometimes be a close fit between what we term a civilisation and a political unit - ancient Egypt, for example - this is not always the case. The many independent groups of Maya, spread across their landscape, shared sufficient aspects of culture, which we deem complex and sophisticated enough for us to see them as a 'civilisation' distinct from others. But cultures and civilisations in these terms seem to be difficult to consider as collapsible units in the same sense as a structured human society - though they are certainly prone to change and transformation and can be affected by the collapse of political units within them, which drive particular aspects of material culture (say literacy or monumental architecture, for example).

Here we should recall the difference between states, societies, and civilisations. It seems clear enough that collapse is something that can best fit political units, human social groups of whatever scale and complexity, but that culture and civilisation are different - they 
are certainly capable of transformation that may sometimes be connected to collapse (and to state formation and increasing or decreasing complexity).

I mention lifestyles, which may seem an odd term to find here, because one of the key ideas underlying most ideas about collapse is that life and/or society gets worse, and becomes difficult or intolerable. This idea of things getting worse is inextricably linked with ideas of decline, and wherever literary texts touch on this subject, we have to consider the possible gaps between rhetoric and reality discourses of decline are often found alongside what others categorise as growth, improvement, and progress. Young and Leemans include this 'discomfort' in their definition of collapse, with its implication that a previous way of life cannot be maintained even if it were desired; and this is perhaps in the forefront of our popular images of collapse as a forced and probably difficult or unpleasant change.

One example of this idea might be the Ik people of northeast Uganda, discussed by Tainter as a case of collapse. He based his discussion on anthropologist Colin Turnbull's dramatic and (in)famous 1972 account The Mountain People..$^{6}$ Elements of the Ik's seemingly extremely selfish and individualistic lifestyle and behaviour, such as allowing immature or elderly relatives to starve to death, shocked Turnbull; these aspects were built upon and discussed by scholars and playwrights, and attracted the attention of the reading public around the world. 57 The Ik appeared almost to be an anti-society, and to represent what could happen when a people were driven to extremes in order to survive, something along the lines of the boys' descent into savagery in William Golding's Lord of the Flies.

It has seemed to many that the Ik represented a classic collapsed society, one with potential to represent the future of humanity. However, this 'apocalyptic' and 'post-apocalyptic' situation came about not because of natural environmental factors, despite the fact that the Ik were affected by a two-year drought at the time of Turnbull's visit, but because they had been barred from their traditional hunting grounds and forced to change their lifestyle, and this left them much more vulnerable to the effects of any drought. Much about Turnbull's presentation of the Ik has been criticised, but the image of a spiral into savagery remains a popular image of collapse one that now tends to be associated with Easter Island, amongst 
other examples..$^{8}$ The Ik collapse - it seems to fit in with some of our definitions - was an unintended outcome of the changing laws of a modern nation.

\section{Systems}

Culture zones, as well as political, social, and economic ones, are really interconnected systems. ${ }^{59}$ A system is a network of some kind, and for places that form part of a system their maintenance (in some form) may become dependent on the survival of the whole or part of that system or its functions. Historians and archaeologists sometimes refer to 'world-systems', because these systems can be regarded as 'worlds' in themselves. ${ }^{60}$ As such, different cultures (or 'civilisations') can be regarded as parts of a system, as well as systems in their own right. The eastern Mediterranean at the end of the Late Bronze Age is an example of such a system, in which states from Greece to Egypt and beyond interacted with each other, with transfer of goods and materials as well as ideas and people. ${ }^{61}$

Systems can break down (i.e., stop functioning in the same way) in a number of ways and for many reasons, and this can affect the ability of other parts of the system to function or continue in the same form. We know this from our experience in the modern 'globalised' world. For example, if there is no longer a demand for goods from place B in place A, an economic specialism in place B may become redundant, damaging its order. If place B's ruler is dependent on a particular return from place $\mathrm{A}$ in order to maintain his position at home, such a change in place A may cause collapse in place B. Systems collapse is, to some extent, a useful way of thinking about collapse, however, it can be difficult to assess the levels of interdependency in world-systems. In the end, we must consider how any change in the system was responded to by a given part of it and whether and why collapse may have followed.

\section{Populations}

Finally, collapse is an idea that is often applied to populations and peoples, where it means a drastic and sudden reduction to very low levels, with consequent social and political effects. This usage is very familiar from ecology - well known now through collapsing 
honeybee populations in colony collapse disorder, as mentioned earlier, but also from the study of population - demography - and from common usage. ${ }^{62}$ Recently, for example, Steven Gray in Time magazine explained that 'The news this week that Detroit's population plunged more than 25 per cent to just 714 ,ooo in the last decade shouldn't be surprising. The city's collapse is as well-documented as it is astonishing - the population peaked at nearly 2 million in the $195^{\mathrm{O}}$, driven in part by a post-World War II auto industry boom now long gone. ${ }^{63}$ But clearly the population of Detroit has not simply disappeared or been wiped out in any apocalypse, rather people have moved in accordance with their ability to make a living and their perceptions of opportunity. Should we expect anything different from past populations?

Although some anthropologists and archaeologists do focus on population-based or palaeodemographic issues - as in a recent volume edited by Patrick Kirch and Jean-Louis Rallu entitled The Growth and Collapse of Pacific Island Societies, for example ${ }^{6} 4$ it can be very confusing when collapse is used generally with the implication that it is primarily a matter of a catastrophic decline in population, as it may be in ecology. Even though conquests and political collapses can result in reductions in overall population in the longer term, and in the redistribution of people in a landscape - away from former capitals or central places - as well as changes in the visibility of people due to changing material habits, these are often effects of collapse or go hand in hand with it as a process. It may look like people are disappearing - but people then, just as now, were mobile and responded to what was happening around them. Population number and distribution can change without being a collapse or causing one.

Colonisation, on the other hand, has very clearly led to episodes of demographic collapse and consequent social collapse. For example, with a population of over three million Taino in 1492 when Colombus arrived at Hispaniola (now Haiti and the Dominican Republic), the population of the island soon crashed to a tiny fraction of that number within a few decades - the indigenous cultures, political organisation, and language largely disappearing too. ${ }^{65}$

There are many features of collapse that can result in population redistribution and decline - warfare uses up people, can reduce the number of elite people (which would affect the make-up, the material culture, and functioning of society), spreads disease, and can make it impossible 
for life to carry on as normal, disrupting agriculture and trade. Defeats and failures in state organisations, or accidental disruptions, can also lead to failure to maintain established agricultural or other systems that contribute to the corporate system - both those that underpin an elite, or elite support of the system, or those that contribute to subsistence in general; without these, there can be famine or a failure of confidence in the status quo. Ideological change too can lead to people moving out from formerly important centres. Populations may, over time, spread out and shrink to fit the resources available, or respond in other ways, such as seeking to expand and commandeer resources elsewhere.

We sometimes have the situation where population collapse and other types of collapse can appear to be the same or be similar, and this can lead to further conflation of two distinct processes. Consider the contrast between the depopulation of Detroit, which we know to be due to economic changes, and the fourteenth-century Black Death in Europe, in which disease killed perhaps half the population of Europe. Both are visible demographic changes. But although to an archaeologist the evidence of abandonment, and limited use of sites, may look the same, the reasons for change in each case are very different. Population change can be both a cause and consequence of other forms of collapse and social change, but demographic collapse or decline, even if it happens suddenly, need not cause political or social collapse.

\section{WHY DOES COLLAPSE HAPPEN?}

There are, of course, a host of explanations that people have put forward to explain collapse, and these will be discussed in the context of the case studies throughout the book. But we can look broadly at some ideas before we start.

Tainter explains collapse by referring to an economic theory, that of declining marginal returns. ${ }^{66}$ In this theory, when the quantity of a particular variable is increased, 'output' initially rises rapidly, but then slows and eventually may decrease. ${ }^{67}$ He expresses this in four moves: (1) Human societies are problem-solving organisations, (2) socio-political systems require energy for their maintenance, (3) increased complexity carries with it increased cost per capita, and (4) investment in socio-political complexity as a problem-solving response often reaches a point of declining marginal returns. 
In other words, societies can initially do well by becoming more complex; adapting to circumstances increases their complexity, which allows them to cope. But societies constantly face challenges, and so by constantly adapting and becoming more complex, they can eventually become over-complex, no longer delivering any benefit, at which point they collapse into more simple systems. What is interesting in this view is that collapse is itself an adaptation - the simpler societies that arise out of collapse are better adapted, and they may themselves start along the path of increasing complexity, suggesting a cyclical process of collapse and regeneration (on some level). However, this explanation still requires a cause - what problems was a given society facing that tipped it over into collapse?

Nowadays, many people associate past collapses with the environment. Indeed, the volume mentioned earlier, Sustainability or Collapse? An Integrated History and Future of People on Earth, based on the results of a Dahlem workshop that involved archaeologists, historians, and sustainability experts, focussed on climate change, environmental damage, and collapse, looking at what might have happened to past societies and the threats and dangers faced by contemporary societies. ${ }^{68}$ These studies build on old ideas. Almost a century ago, in 1917, Ellsworth Huntington proposed that climate change had undermined the agricultural base of the Roman Empire. ${ }^{69}$ Huntington, pioneering scientific methods still used today, used data based on tree ring records as proxies for climatic conditions and changes. More recently, in 2001, Harvey Weiss and Raymond Bradley published a famous and influential paper in the journal Science, where they argued that many ancient collapses were probably caused by climate change..$^{\circ}$ This view has recently been reasserted by Michael Marshall in his 2012 article in the New Scientist..$^{1}$ This environmental approach to collapse is common, indeed it seems dominant, and this is no surprise given our own contemporary environmental concerns. ${ }^{72}$

However, many, though not all, archaeologists remain sceptical about climate change explanations of collapse - certainly when they are applied as single cause theories.73 This is not because archaeologists are ignorant of these theories (indeed, some have pioneered them), or because they have closed minds, or are unwilling to consider different kinds of evidence, but simply because they view collapse as a human story, one that is much more complex than the 
equation 'climate changes = societies collapse'. Climate change, when it happens (as with earthquakes), can also have very different effects in different, even proximate, locations.

Another problem often pointed out is that it can be very hard to tie down climate changes with any chronological precision, therefore it is difficult to associate them securely with political and societal changes. In this vein, there has been a tendency among supporters of climate change explanations to see correlation as causation - that is, when evidence indicating possible climate change seems to coincide with collapse, it is assumed to have been a causal factor in that collapse. Despite doubts about climate change-based explanations, no archaeologist would deny that agriculture-based societies - all pre-industrial societies - would have been vulnerable to bad years too much or too little rain, excess cold and frost, and so on, that would potentially cause social disasters and destabilise societies. Even so, complex societies are often geared to offset such problems, for example, by relying on polyculture rather than monoculture, which would reduce the chance of total crop failure, by storing produce as an insurance, and by arranging for imports of food. Often, there is also ambiguity over whether climate changes were sudden shocks (i.e., events that happened at a point in time) or less dramatic shifts over time (the average for a period differs from earlier and later periods' averages) - the former would clearly be harder to cope with.

Readers of environmental histories, such as Clive Ponting's A Green History of the World, originally published in 1991, will be familiar with the notion that ancient societies cause their own collapse by destroying their own supporting environments, perhaps by deforestation or over-intensive farming, or a combination of 'ecocidal' behaviour.74 This has been a theme of Jared Diamond's work too, not only in Collapse, but also in his book The Third Chimpanzee (1992), and in a 1994 paper entitled 'Ecological collapse of past civilizations'.75 He advanced the idea that 'self-destructive abuse of our environment, far from being a modern invention, has long been a prime mover of human history'. ${ }^{6}$ Others, such as Sing Chew, have focussed on this, advancing the idea of cycles of societal development, environmental degradation, collapse, and environmental recovery. 77 This line of thinking is found in archaeology too American archaeologist Charles Redman's book Human Impact 
on Ancient Environments discusses a range of examples of proposed ecocide, including the Puebloan culture and Rapa Nui..$^{8}$

There is nothing new in such theories, whose modern origins date back to the work of George Perkins Marsh and his 1864 book Man and Nature - Marsh gave historical examples of land degradation and warned that humanity might reduce the Earth to the barrenness of the moon. ${ }^{79}$ Later, in 1916, Vladimir Simkhovitch advanced the theory that Rome collapsed because of agricultural exhaustion; his argument owed its origins to quotes from Latin writers on agriculture and to recent developments in agricultural and soil science. ${ }^{80}$ But although humans have always modified the natural environment, and the modern agricultural and industrial revolutions have done this on an increasingly large and harmful scale, coincident with massive and unprecedented population increase, it is certainly far from clear that many, or indeed any, of the ancient states that collapsed did so because they caused environmental damage that undermined their ability to exist. Even so, climate and ecocide arguments for the fall of the Roman Empire, and other collapses, can still be found embedded in modern research and historical narratives even a century and more after they were first proposed, with scholars in many fields seeking to build up scientific, especially palaeoclimatic, data ${ }^{81}$

Although Diamond set out to write his Collapse book explicitly focussed on the environment and collapse, where historical examples would provide instructive parables, he had to concede that he knows of no 'case in which a society's collapse can be attributed solely to environmental damage', and even that 'it would be absurd to claim that environmental damage must be a major factor in all collapses ... It's obviously true that military or economic factors alone may suffice' ${ }^{82}$ For this reason, he provides a number of factors that could cause or contribute to collapse, three of which are environmental: (1) Environmental damage, (2) climate change, (3) societal responses to environmental problems; other factors are (4) changes with trade partners and (5) hostile neighbours. Even so, the tone of the book is clearly geared towards the notion that collapse is often caused by environmental damage. He claims, for example, that 'deforestation was a or the major factor' in the Rapa Nui, Ancestral Puebloan, Classic Maya, and the Greenland Norse collapses. ${ }^{83}$ Overpopulation should also be added to Diamond's list of factors, since it plays a key role in many of his explanations. 
With both Tainter's and Diamond's 'grand theories', a precipitating factor is still often necessary to set off the spiral of collapse - invasion, inflation, and loss of tax revenues sparked the demise of the Western Roman Empire, whose complexity finally stopped paying off. With the Classic Maya, Ancestral Puebloans, and the Greenland Vikings, climate change tipped these societies into collapse. In a Malthusian scenario, Diamond has the Rapa Nui, Ancestral Puebloans, and Classic Maya societies overpopulated, deforesting their environments and causing soil erosion, which undermined the subsistence basis of their societies - as population increased, the capacity of the land to support it decreased. This brought about violence, depopulation, and collapse. The final factor was the failure of rulers and elites to manage the situation - a warning to our modern powers that be.

Explanations of collapse that rely on overpopulation and the outstripping of resources are known as 'overshoot' models, and these have been critiqued by Tainter in his 2006 paper 'Archaeology of overshoot and collapse'. ${ }^{8}$ He suggests that there 'does not presently appear to be a confirmed case of overshoot, resource degradation, and collapse brought about by overpopulation and/or mass consumption'. Overshoot models strongly reflect contemporary interests, and, as Tainter suggests, 'many of the most ardent proponents are outside of archaeology'. A recurring criticism in the environmental turn is the tendency to see populations as either unwitting victims of natural circumstances, such as climate change, or as ignorant and irresponsible ecocidal architects of their own doom.

The model of apocalyptic ecological collapse and historical change a la Diamond has been questioned by archaeologists and anthropologists in a 2010 book, Questioning Collapse, edited by Patricia McAnany and Norman Yoffee, and contributed to by other archaeologists, and at a Cambridge archaeological conference held in 2010. ${ }^{85}$ Diamond himself reviewed Questioning Collapse in the journal Nature and was unsurprisingly critical of it - this led the editors and authors of the book to complain to Nature about the conflict of interest in asking him to review their book, which was composed as a direct response to his work (Figure 1.2). ${ }^{86}$ Other researchers have also questioned the idea of climate and ecocidal collapse. W. H. Wills, Brandon Drake, and Wetherbee Dorshow recently published a paper in PNAS where they conclude that neither ecocidal practices, such as deforestation, 


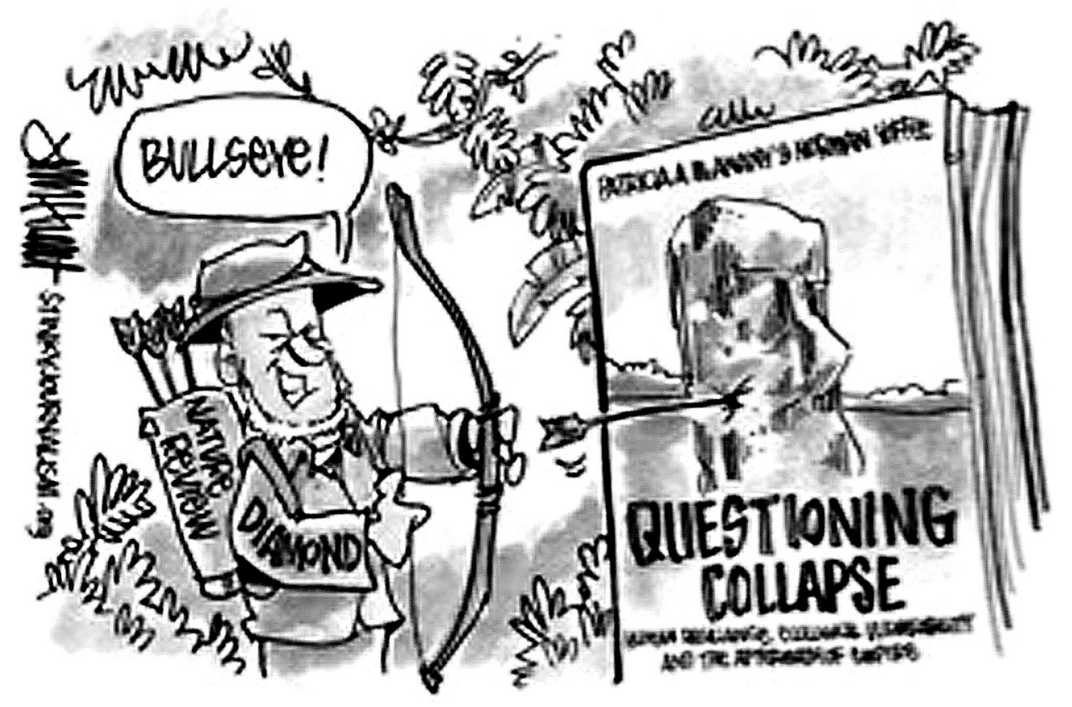

FIGURE 1.2. Jared Diamond vs Questioning Collapse.

Source: Cartoon by Jim Hunt.

nor climate change caused collapse and depopulation at Chaco Canyon. They warn that it 'should not be used as a cautionary story about socioeconomic failures in the modern world' ${ }^{87}$

Often collapse is presented, especially in the popular media, as having a single major cause - whether it be a natural disaster like climate change, drought, or ecodical environmental damage; or a human cause like corruption, invasion, or popular revolt; or economic factors. A fairly representative list of causes, referring specifically to the Classic Maya collapse, but relevant in considering many other collapses, has been compiled by James Aimers (Table 1.3).

Despite a popular fixation on finding 'the cause', archaeologists tend not to think about collapse in such a cut and dried way. In his recent book on Late Bronze Age collapse in the eastern Mediterranean, Eric Cline has quite properly explained how uncertain things can be:

There is little doubt that the collapse of the Late Bronze Age civilizations was complex in its origins. We do know that many possible variables may have had a contributing role in the collapse, but we are not even certain we know all of the variables and we undoubtedly do not know which ones 
TABLE 1.3 Proposed causes of the Classic Maya collapse

\begin{tabular}{ll}
\hline Environmental & Socio-political \\
\hline - Climate change/drought & - Change in trade routes \\
- Deforestation & - Competition from Central Mexico \\
- Disease/plague & - External explanations \\
- Earthquakes & - Intersite warfare \\
- Ground slope change & - Invasion with/without resettlement \\
- Hurricanes & Peasant/class revolt \\
- Insect infestation/plant blight & - Political-ideological pathology/ \\
- Overpopulation/subsistence & fatalism \\
- stress & \\
- Soil erosion/loss of fertility/ & \\
- Volcange to untillable savannah & \\
\hline
\end{tabular}

Source: Page 333, Aimers, J. J. (2007). 'What Maya collapse? Terminal Classic variation in the Maya Lowlands.' Journal of Archaeological Research 15: 329-377.

were critical - or whether some were locally important but had little systemic effect ... There probably was not a single driving force or trigger, but rather a number of different stressors, each of which forced the people to react in different ways to accommodate the changing situation(s). ${ }^{88}$

For Cline, causation is complex - and, as he points out, we often do not know how to weigh up the factors involved or even that we are aware of all of them. His sentiments apply just as much to other instances of collapse. Arthur Demarest too notes that causation is layered - many factors at different levels may be involved. ${ }^{89}$ There may be proximate causes as well as deeper structural issues. The structure, for example, ideology, of a society could determine the range of responses to a given proximate problem. In collapse, we are likely to be seeing multiple factors (rather than competing mutually exclusive explanations), proximate and structural, feeding back into each other and responses may have had unpredictable outcomes - the situations would have been dynamic.

Finally, we must not forget the role that chance plays in survival or collapse and the role of human actors in reacting and shaping events. Herbert Kaufman reminds us of these:

Chance obviously played a large part in the success or failure of states ... A combination of favorable circumstances could catapult one system to the summit and keep it there for a long time; a sudden misfortune might drag a system from its day in the sun after a short interval. That is not to say that the 
people in positions of responsibility in the overarching polities had no influence on their own fate; their actions could certainly exacerbate difficulties or take advantage of opportunities. $9^{\circ}$

While people will always be tempted to create a grand theory, or push a particular explanation of collapse, the truth will always be more complex - perhaps more complex than we can reconstruct.

\section{SYSTEMS, CYGLES, AND RESILIENGE}

Some of the recent work on collapse emphasise that there are normal cyclical patterns visible in history - and suggest that the rise and fall of organisations like states or empires, or their formation and collapse, are inevitable and repeating processes. The theory of cycling is not new, as we saw earlier in this chapter, and like many theories, they themselves 'cycle' in and out of fashion.

In collapse studies, cyclical-type theories can be found coming from historical theory, from archaeologists, and from ecology and biology. In what follows, a few of the major contributions will be discussed, beginning with archaeologist Joyce Marcus' dynamic model. After that, we will look at the approach of scholars who adopt a worldsystems approach. Finally, we will examine an approach that has come to the fore recently for its application to sustainability studies that of resilience theory.

\section{The Dynamic Model}

One model that emphasises the constancy of change in human communities is known as the dynamic model. This was originally developed by archaeologist Joyce Marcus to describe an apparently recurrent pattern identifiable in Maya states, how they grew, extended their power, and fragmented into smaller states - consolidation, extension, and dissolution..$^{{ }^{1}}$ When other archaeologists noted that the model seemed to fit their study areas too, she extended it to other Mesoamerican cultures and eventually to the Andes, Mesopotamia, Egypt, and the Aegean. In her view it seemed at least to fit with what happened to many ancient states, if not all.

Marcus noticed that Maya states seemed to be dynamic - over time, they appeared to follow a pattern of formation, expansion, and 
breakdown. Maya chiefs competed with their neighbours, and out of this competition larger states were formed. Major states based at Tikal and Calakmul appeared when they managed to dominate their neighbours militarily and diplomatically. In this way they expanded their influence territorially over already existing cities, and also new sites were developed. However, these bigger agglomerations did not last long before breaking up again into more or less independent smaller polities. Subsequently, some of these smaller polities, like Dos Pilas, also expanded in the same way. At their largest, states had a four-tier hierarchy of sites - the top three had administrative functions and hereditary lords, eventually all broke down to have only three tiers.

Marcus argues that this model captures the rise of states in the Early Classic period and the breakdown of some of Maya states in the Peten region in a period known as 'the hiatus' (AD 534-593). States that formed in the Late Classic - second generation states such as Dos Pilas - were often based in areas that had been provincial parts of earlier states. These states also collapsed between AD 800 and 1000 (the Terminal Classic), but other states were being formed at the same time in Belize and the Puuc region of Yucatan. Later still, Chichen Itza, and then Mayapan, formed states which also collapsed, leaving the Maya region divided into sixteen regions with a dispersed population.

One advantage of the dynamic model is that it presents periods of state formation and collapse as a normal process. And as Marcus points out, what is interesting is the variation in the duration of peaks and troughs, which we consider in hindsight to be normal. For example, she suggests that Mesoamerican field archaeologists consider the 200-year 'peaks' - periods where bigger unified states existed - to have been normal, whereas Mesopotamian epigraphers consider the long periods of disunity, where Mesopotamia was fragmented into numerous smaller polities, to have been normal, with unified states or empires unusual and short-lived..$^{2}$ Similarly in Egypt, China, or Japan, 'intermediate periods' or 'warring states' periods represent 'unusual' episodes of fragmentation in 'normally' unified states. In the Korean region, we can also find patterns of unity and fragmentation as kingdoms were forged and fragmented. ${ }^{93}$

Similar episodes of unity and fragmentation can also be found in the Roman Empire. ${ }^{94}$ The so-called third-century crisis involved 
persistent internal warfare and invasion from the Levant all along the northern borders of the Roman Empire to the North Sea. Between the murder of Alexander Severus in AD 235 and Diocletian coming to power in $\mathrm{AD} 284$ there was a period of chronic instability in which armies repeatedly raised generals to the position of emperor. It also saw the fragmentation of the Roman Empire into three independent state structures. In addition to the 'official empire', Postumus, governor of Lower Germany, founded the Gallic Empire in the west, which lasted from AD 260 to 273, incorporating Germany, Gaul, Spain, and Britain. In the east, Odenathus and his widow Zenobia expanded Palmyrene power, briefly forging an empire within the empire that stretched from central Anatolia to Egypt.95 The Roman Empire was reunified by Aurelian but suffered periodic secessions and was officially divided by Diocletian; thereafter it fluctuated between unity and disunity and fragmentation.

However, some point out that it is obvious that polities would rise and fall and that many do not go through cycles - they collapse, and that is the end of it. Furthermore, the 'cycle' does not repeat in many cases, thus it is not really a cycle. Demarest observes that the Maya collapse was not a cycle, it was 'a unidirectional series of steps of fragmentation', so the model is wrong. ${ }^{6}$ The Mycenaean collapses also led to the end of states and these did not regenerate - the rise of Greek polities much later on was a distinct step in itself and was based on new principles - we can only view it as a cycle if we take a very broad, and not very useful, perspective. The model also does not explain why collapse happens.

\section{Asabiya and Secular Cycles}

A view of cycles of change was developed in the fourteenth century by the Tunisian Arab historian Ibn Khaldun (AD 1332-1406), who outlined his view of the rise and fall of states in his Muqaddima.97 His theories have inspired and been taken up and extended by modern scholars such as E. N. Anderson and Christopher Chase-Dunn, and Peter Turchin, with reference to the rise and fall of empires and states. $9^{8}$

Khaldun thought that the property of asabiya, a kind of feeling of group solidarity, was behind the successful formation of states. 
Over time, though, following the process of formation, asabiya would naturally reduce, leading to weakness, fragmentation, and the collapse of a dynasty. New groups with stronger asabiya, often nomads from the desert margins, would take over and form new ruling dynasties - effectively new states - and the cycle would repeat. The scenario reminds me of a story told by Herodotus, in which it could be said that asabiya was generated. ${ }^{99}$ In the aftermath of the Assyrian Empire, from which numerous peoples had been trying to gain their independence, Herodotus describes the rise to power of Deioces the Mede. Deioces made himself indispensible amongst the Medes by gaining a reputation for dispensing strict and impartial justice, and increasing the number of people obliged to him. He then withdrew his services, causing lawlessness to return, but by 'popular demand' he was asked to return as king - and ruled justly for fifty-three years.

Anderson and Chase-Dunn note the repeated invasions and takeovers of China by nomadic outsiders 'in regular Ibn Khaldun cycles'. ${ }^{100}$ They apply these cycles to a number of ancient and more recent examples, including the Soviet Union and even the USA, both of which they claim have gone through classic Ibn Khaldun cycles, though the USA clearly has not collapsed. Without the element of invasion from the outside, they instead posit some kind of 'internal renewal'. They also draw Khaldun into world-systems theory and offer a host of more immediate explanations for collapse, which draw on ecological literature giving an important role to climate change, deforestation, disease, as well as war and shifting trade connections.

Turchin, a population biologist, focuses on historical dynamics in his term cliodynamics, the mathematical modelling of historical changes - and looks at asabiya, demographics, and the territorial expansion and contraction of empires, taking a cue from the work of Rein Taagepera, who attempted to quantify such factors in the 1970s. ${ }^{101}$ A key to his work can be found in a quote from George Puttenham in 1589 , which expresses the cycle:

peace makes plenty, plenty makes pride, pride breeds quarrel, and quarrel breed warre: Warre brings spoile, and spoile povertie, povertie patience and patience peace: So peace brings warre and warre brings peace. ${ }^{102}$

In a later book, Turchin and Sergey Nefedov begin their account by discussing Malthus and demographic cycles, and develop a cyclical 
model of historical change involving expansion, stagflation, crisis, and depression, which they applied to various ancient and more recent dynasties and states, including the Roman Republic, Plantagenets, Tudors and Stuarts, and the Capetians. They attempted to quantify historical data and argued that 'the general implications of our results ... are that some sort of general regularities of the historical process appear to exist'. ${ }^{103}$ They mention both state collapse and demographic collapse, for example, they note that medieval France and western Europe:

was literally crammed with people. The 'ecosystem' ... was strained to breaking point and on the verge of collapse. The collapse experienced during the fourteenth century was the result of a typical concatenation of famine, pestilence, and war. ${ }^{104}$

Is it really surprising though that we find that human societies have gone through similar processes? We might ask why the process led to collapse in some cases but not in others. And should we really identify a collapse in fourteenth century Europe? It depends on what we mean by collapse. Despite demographic collapse in the fourteenth century, states essentially continued their development, and populations later became larger than they had been before.

It is possible that Turchin's roughly three-century cycle could be applied to ancient empires such as the Hittites, and possibly others, and could reveal factors worth investigating further in examples of collapse. But we should look at each instance of collapse rather than assume the model to be correct. And how roughly or precisely do we measure three centuries? The Hittite state lasted a little longer than four, as did the Roman Western Empire, so can these count? Change and vulnerability rather than stability and strength may have been the norm in most cases - where we do find a period of apparent stability over the long term, it may be due to chance, as Kaufman suggested. ${ }^{105}$

These 'cliodynamic' works tend to be quite removed from the archaeology and primary history of past societies, dealing in big patterns and systems, and the more abstract they become, the less convincing (or surprising) they appear when scrutinised. Although Turchin and Nefedov clearly allow that phases of the cycle blur into one another, have different scales, and also allow for the actions of individuals, how the many different kinds of unpredictable contingent 
'causes' can be included in a single model is unclear. Nevertheless, the patterns they identify may be real enough, taken as approximations, if unsurprising. Systems history can sometimes be accused of simply telling well-known stories in the language of a particular theory.

In some cases, especially in 'big' history, the facts of 'what happened' are not established enough (or can be seen from multiple perspectives rather than a single narrative) to draw off a theory at a higher level convincingly. The conclusions of historical demographics, especially when using data derived from archaeology, are notoriously ambiguous (basically applying a preferred formula to habitation or funerary evidence). Quantifying 'history' to develop 'scientific' theories of history is something people have tried to do, but it rarely goes uncriticised and is often not convincing. Take asabiya, for example. As Tainter points out in one review, 'states ... inculcate something like asabiya in their armed forces'. ${ }^{106}$ Roman soldiers' 'love' of their standards is well known, so why should the Roman Empire have collapsed when asabiya was strong? Asabiya in nomadic (or peripheral) groups was often not enough for them to effect a takeover. Asabiya, or a notion of common cause, is an interesting way of understanding or expressing the shared belief in a system that people can have, but it will never be straightforwardly quantifiable.

Sustainability, Resilience, and Resilience Theory

The achievement of sustainability is a current target for many human societies on a number of scales. ${ }^{107}$ Nations seeks to promote and achieve sustainability in agriculture and food supply, economic growth, and power generation, while also attempting to create sustainable communities for citizens to live in. Sustainability is not just an aim at the national level, but also at an international governmental level, and amongst private companies, and others. Sustainability is promoted as a social good by charities, in education, in research, and in the media. A sustainable society is by definition one that will not collapse but will carry on indefinitely, being able to adapt to change; and because of this, sustainability studies are directly connected with the idea of collapse. The whole backdrop of human history is now seen as a database for studying the sustainability of human communities. 
In the debate about whether collapse is a useful concept for thinking about past societies and historical change, the concept of resilience has come to the fore. It is a key theme in McAnany and Yoffee's Questioning Collapse. ${ }^{108}$ However, resilience can also be a confusing concept, for it too, like collapse, seems to be used in different ways. Technically, resilience theory is a metaphorical description intended to model changes in ecosystems as long-term adaptive cycles. It incorporates ideas of change that occur on multiple levels and at different scales, including sudden catastrophic change.

Resilience theory was developed by C. S. Holling in the 1970s; although it was initially applied to ecology, it has since been applied by social scientists, including archaeologists, to try and understand a range of systems including economics and human societies. ${ }^{109}$ It is currently a favoured approach to sustainability studies. In resilience theory, resilience is defined as:

the capacity of a system to absorb disturbance and re-organize while undergoing change so as to still retain essentially the same function, structure, identity, and feedbacks. ${ }^{110}$

We can imagine this applied to societies that can retain some essential 'essence' of themselves whilst absorbing shocks, with collapse representing an inability to do so without losing the 'essence', resulting in changes of structure and identity. Again, the implication seems to be that 'disturbance' might equal external shocks to the system, rather than internal change.

Some archaeologists also emphasise human resilience, but in a more general sense, and they position this as oppositional to the idea of collapse. It indeed sounds obvious enough that something which is resilient is sustainable, and therefore not prone to collapse. In the words of McAnany and Yoffee ${ }^{111}$ : 'on close inspection of archaeological evidence, documentary records, or both, it becomes clear that human resilience is the rule rather than the exception.' In this sense they are suggesting that human populations rarely disappear.

However, resilience theory does not really mean that collapse or other kinds of change are unusual or uncommon, but rather it includes collapse as part of a normal cyclical pattern that may be identified in systems of various kinds in which constant changes may be taking place on different levels. Collapse can lead to innovation and change, as Brian Walker and Paul Salt explain: 
'Creative destruction' is a term now used to describe the disturbances that periodically punctuate the adaptive cycle. It breaks down stability and predictability but releases resources for innovation and reorganisation. ${ }^{112}$

This is similar to historian Shmuel Eisenstadt's statement in his chapter of The Collapse of Ancient States and Civilizations:

the investigation of collapse in ancient states and civilizations really entails identifying the various kinds of social reorganization in these types of societies and so viewing collapse as part of the continuous process of boundary reconstruction'. ${ }^{113}$

Thinking about societies from the perspective of resilience theory means firstly acknowledging that human societies are really socialecological systems. Any society relies on ecosystems (of which they are part) for its existence. This means local environments, but also perhaps those further afield, and effects between ecosystems and social systems, which feed back into each other in complex ways. We also have to consider that any particular 'society' that we identify is just one possible arrangement of people and the environment.

Applying Walker and Salt's definition of resilience to a human society, we can think of resilience as a kind of buffering capacity: the more resilient a society is, the better it can sustain 'disturbances' whilst remaining identifiably itself. This means it should be flexible enough to change and adapt without disintegrating or transforming beyond recognition. For example, Japan was affected by a massive earthquake in March 2011, followed by a tsunami which devastated the north east of Honshu. But Japanese society was able to absorb or buffer many effects of this disaster through its economic and organisational capacities. Although changes and adaptations followed these events, Japan has not collapsed or transformed into a new entity (we might consider changes to energy production as 'structural changes' though). Other societies affected by disasters may not be able to sustain them without serious transformation or collapse, which then becomes an adaptive trait.

To lose resilience, then, is to become prone to collapse - Charles Redman, an archaeologist with a long interest in human-environment relations, notes:

the long-term history of human-environment interactions contained in the archaeological record reveals that many human responses and strategies, 
although apparently beneficial in increasing production in the short term (even over a few generations), nonetheless led to a serious erosion of resilience in the long term, resulting in the collapse of both environmental and social systems. ${ }^{114}$

Redman explains that in resilience theory change is episodic, rather than either continuous and gradual or chaotic, which is reminiscent of geological catastrophism. There are forces of stability which promote continued productivity and forms of capital and social memory, as well as destabilising forces which create flexibility, diversity, and opportunity. In combination, these may sometimes appear to create an equilibrium. Taking a fixed approach to maintaining 'constant yields' without attention to context leads to the loss of resilience in other words, changing circumstances may render a once welladapted system maladaptive - suddenly unable to function. From a sustainability point of view, being able to adapt is the key - not just maintaining the status quo.

The adaptive cycle is represented by resilience theorists as passing through four phases, usually represented 'scientifically' as a figure eight, beginning with exploitation (r), in which an area is colonised (a biological/ecological theme). This is followed by the conservation phase $(\mathrm{K})$, in which energy and material continues to be accumulated and stored. In the omega phase $(\Omega)$, there is increased population and environmental degradation, which is followed in the alpha $(\alpha)$ phase by reorganisation. Collapse may be a feature of the omega or alpha phases, depending on how one interprets the figure.

McAnany and Yoffee's perspective on resilience becomes more clear when we read that:

Resilience means that some kinds of change, especially political change, can be quick and episodic, whereas other kinds of change, for example changes in kinship structures and belief systems, can be slower moving. Both kinds and different paces of change can coexist. ${ }^{1{ }^{15}}$

In other words, it is again the definition or parameters of collapse that are in question, and as we have seen, collapse is sometimes defined as a political process, sometimes as a demographic one. The distinction made between such phenomena as kinship structures and belief systems and political change is a relevant one though, and it recalls a distinction made by anthropologists between 'great' 
and 'little' traditions. Great traditions are those that have been associated with 'civilisation', elites, and urbanism, whereas little traditions are regarded as more basic and fundamental ways of life in more rural subsistence settings. It is, as we have seen, principally the loss of things associated with great traditions, which we, in hindsight, often see as the 'essences' of a society, that often defines collapse - continuity may well be observed in 'little' traditions in many cases.

There seems sometimes to be a confusion when thinking of resilience and resilience theory. Collapse is a normal stage in the resilience theory model of a cycle of change, yet at the same time the property of resilience itself is a measure of resistance to collapse. Cultures can be resilient in the sense that they retain a recognisable form, but sometimes cultural or social change is an adaptive collapse to a different system, but with a resilient population, who may develop a very different culture.

Another problem in the way resilience theory is applied to archaeology is that it tends to retain and emphasise a biological or ecological focus - that is, it focuses on the human-environment system without paying too much attention to the complexities of social systems themselves or how these are represented by their material culture. This means that resilience theory tends only to be deployed in terms of subsistence strategies and patterns - population and human-environment relations in particular. Explanations of collapse tend to be based on imbalances or disturbances that come up in, and between, these systems, where short-term productive gains are usually said to create overpopulation. In that situation, any disturbance, such as a climate event, causes the collapse - a shock that the system cannot absorb without profound change.

In these explanations there is an aspect of internal and external causation: a social and developmental trajectory based on successful adaptation, but that renders a society unsustainable in the long run because of increased vulnerability to shock, usually an external event. These shocks do not need to be external events, nor, strictly speaking, does the narrative need to be based only on subsistence elements of the society. Social relationships and identifications are also defining elements in societies, and the breaking of these, for whatever reason, can also create collapse as a result. 
There are two helpful aspects of the resilience theory model, though. The first is that it incorporates a reorganisation phase in the alpha stage of the cycle following collapse. For although it is common enough to see a post-collapse phase as some kind of dark age, this term often obscures what is actually going on at the time. Collapse itself can even be seen as a necessary reorganisation, an adaptation in itself.

Resilience theory seems reminiscent of catastrophism in that there is unpredictable episodic disruption to systems. Indeed, it could be argued that resilience theory simply offers a new way of talking about the same themes that have already been addressed in collapse studies. Collapse in the model of resilience theory still requires some kind of external disturbances, and it is argument about causation that collapse studies have tended to revolve around. So in the end, resilience theory may not offer anything very new in terms of explaining how collapse comes about.

\section{AFTER COLLAPSE}

In a 1999 work, Tainter discussed post-collapse societies. ${ }^{116}$ It might be generally thought that 'dark ages' should follow collapse, but Tainter cautioned that, like the term collapse, it 'is ambiguous and should be used with care'; he associates it with the 'declines in literacy, writing, and communication that often result from collapse'. ${ }^{117}$ But to archaeologists, 'dark ages' are also periods which we know less about because there are fewer remains (as well as texts) for us to see - but neither of these mean that there were no people, or that nothing was going on. The term 'archaeological invisibility' is useful here. Rulers and elites are usually more visible (materially speaking) than the majority of the population, so periods after collapse can seem darker as elite culture disappears. Tainter makes the important observation that collapse is something that often affects social elites and ruling classes more than other sectors of society - 'dark ages, for most people, were only slightly less luminous than preceding periods'. Archaeologist Colin Renfrew agrees that as well as a loss of central administration and a loss of social and political complexity, collapse has often involved the 'disappearance of an elite'. ${ }^{118}$ This is something that many archaeologists agree on. 
People who study collapse are not, therefore, interested only in endings. Schwartz and Nichols' edited volume After Collapse: The Regeneration of Complex Societies (2006), deals with both collapse and also its aftermath. ${ }^{19}$ This focus derives not only from a dissatisfaction with the idea that collapse is just an ending, simply a prelude to dark ages, but also from the comments made by Shmuel Eisenstadt, quoted earlier, about collapse being a process of reorganisation.

Endings, he argued, were also occasions of restructuring, and of new beginnings; in every collapse, there is also continuity and innovation. Implicit in this view is that collapse is rarely the apocalyptic catastrophe it is often presented as; there are still people and social memories and bonds, these people remember the past and recreate or discard elements of it as it suits them in their negotiation of new and meaningful identities and relationships. And collapse is often followed by the continuation of complex society on a different scale, or of the eventual regeneration of complex or large scale societies.

One of the most useful general concepts to come out of the book, which deals with several specific examples, is an idea developed by Bennet Bronson, writing about collapse and regeneration in Southeast and East Asia. ${ }^{120}$ He discussed how complex societies regenerate according to three patterns. First, there are two forms of 'false regeneration'. The first is when a new complex society arises in the same area as an earlier one, but there is no historical link between them. The second is when the centres of a regional society appear to collapse and new ones arise within a given area, but this 'intrinsically evanescent' system itself is stable or constant. Then there is 'stimulus regeneration'. In this case, the development of a complex society is based on people's ideas about the past - ideas which may not necessarily be accurate. For example, it may be remembered through folk memories or known (say, through impressive physical remains) that a more complex society once inhabited an area, which stimulates later rulers to try and develop a new one. The final type is 'template regeneration', in which there are sufficient memories, writings, and so on to make it possible to regenerate a complex state on the model of an earlier one. Bronson suggests that the best example of this is the repeated collapse and recreation of Chinese imperial dynasties - essentially different but very similar empires; 'the key was widespread literacy and the existence of accessible historical records that 
provided a sufficiently detailed blueprint for the pre-existing system to be more or less fully reconstructed'. ${ }^{21}$

\section{WHY IS COLLAPSE IMPORTANT?}

Many archaeologists actually shy away from collapse, partly because it can attract a 'lunatic fringe' and can distract us from the serious business of learning about or presenting the past. Many are dissatisfied with the popular versions of collapse but are rarely called upon to give their own verdicts, at least outside of scholarly publications, conferences, and workshops. Most archaeologists' stories of collapse would fit far less well into the modes of narrative described at the beginning of this chapter. Nevertheless, history and archaeology are riddled with things we call (for better or worse) collapse, with beginnings and endings, with transformations, and with continuities and discontinuities; for me, these cusps have always held a particular fascination. What is it that makes period $\mathrm{x}$ period $\mathrm{x}$, and not period $y$ ? How and why did we get from one to the other? To what extent do these periods exist only in our minds? These are important, even key, questions for those who study the past.

Collapse, despite its mixed academic reputation, is one of the challenging and exciting areas of archaeology, one that brings up a host of other questions that require attention - including the questions of what exactly it was that was collapsing and exactly how collapse proceeded - what variables were present, how they might have interacted, what forms it took, and why. A recent project to try to determine 'archaeology's most important scientific challenges' recognised the importance of collapse studies; the group came up with a category of 'resilience, persistence, transformation, and collapse', and in it they set the question: 'can we characterize social collapse or decline in a way that is applicable across cultures, and are there any warning signals that collapse or severe decline is near?'122

Another reason that collapse is important relates to the use of collapse as a parable or example to be learned from. Since it is a given that people will seek to use historical examples to make cases about the present and future, one way or another, and even that policy may be based, to some extent, on historical examples, we should expect 
that the history is as accurate as it can be. The descriptions we saw Lester Brown give in his book are the same as those presented in the European Commission's Water for Life initiative booklet, published in $2003 .{ }^{123}$ That document, aimed directly at affecting our contemporary behaviour, reported how Sumerian civilisation was 'undermined' by food scarcity while 'overfarming, deforestation with soil erosion and loss of productivity' led to 'the complete demise of ... [Maya] society by AD 9oo'. These views of Sumerian and Maya collapse can indeed be found in some archaeological and historical writing, but these narratives can in particular be traced back to popular environmental histories of the 1990 and beyond. ${ }^{124}$ They have become fossilised into 'new' books (and other media representations) by authors who are largely unaware of the breadth of archaeological research and views. For readers not up-to-date with the archaeology, their content might be taken as an accurate representation of current ideas.

As we look more closely at how collapse is conceived and explained, it becomes apparent that the reality of many popular collapse narratives can be less than satisfying. The Ethiopian famines with their devastating effects on human life and society were not simply natural disasters, not simply caused by a reduction in rain or environmental mismanagement that meant the population could no longer be supported. As Alex de Waal has stated, 'the repeated famines that have struck Ethiopia, and in particular the great famine of $198_{3}-5$ were in large part created by government policies', and this was during a period of some thirty years of civil war and political instability. ${ }^{125}$ If we accept that the Maya simply died and their civilisation ended because of an environmental change, or we label them as ecocidal 'failures', we do a disservice to the people who lived at the time and after, and to their modern Maya descendants who still live, in their millions, in Mesoamerica to this day, and we also leave much of the stories of collapse and transformation untold.

\section{FINAL THOUGHTS AND MOVING ON}

This long first chapter has covered a lot of ground. So far, we have explored a little of how collapse is often presented to us via the news, and how such narratives of collapse tie in with the kind of stories we are used to and like to hear, whether they be in the realms of 
infotainment, spectacle, or tragedy. We have also explored some of the different ways that scholars define collapse and the things they apply the term to, taking a look at some broad explanatory, descriptive, and theoretical models of collapse. We have already encountered the idea that collapse is a complex phenomenon, as Mortimer Wheeler observed decades ago in his discussion of the Harappan civilisation, and as Eric Cline recently stated of collapse in the eastern Mediterranean in the Late Bronze Age.

As with other books and publications on collapse, we will examine a range of examples - fifteen to be precise - some well known, others less so. I hope to put in context what was collapsing, and examine the ways in which scholars have characterised what was happening and how they have sought to explain each collapse. I try also to refer to what happened next - the aftermath of collapse. Although no grand theory of collapse is presented, I take a critical perspective of ideas in each case, and, throughout each chapter, I hope to give the reader an idea of who is saying what and why - giving voice to those researchers who work on and think about collapse and transformation. Even though it is rarely, if ever, possible to be precise or succinct about a collapse, which some might find dissatisfying, I hope readers will, by the end of the book, feel better equipped to make up their own minds about collapse. 